\title{
Estimation of the Thermal Fatigue Resistance and Creep Properties of the Co/Ni-Bearing SAC305 Lead-Free Solders by the Strain Rate Change Tensile Test
}

\author{
Fangjie Cheng ${ }^{1,2}$, Hiroshi Nishikawa ${ }^{2}$ and Tadashi Takemoto ${ }^{2}$ \\ ${ }^{1}$ Materials Science and Engineering School, Tianjin University, Weijin Road 92, Tianjin, 300072, P. R. China \\ ${ }^{2}$ Joining and Welding Research Institute, Osaka University, Ibaraki 567-0047, Japan
}

\begin{abstract}
In the present paper, in order to evaluate the creep properties of $\mathrm{Co} / \mathrm{Ni}$-bearing SAC305 lead-free alloys, the strain rate change tensile (SRCT) test was conducted. Two parameters, $m_{0}$ and $k$, obtained from the SRCT test could be applied to estimate the thermal fatigue resistance and the creep properties for lead-free solder alloys. The $m_{0}$ value implied the material's creep resistance, and the $k$ value revealed the stability of the creep resistance during the whole tensile test process. The Co/Ni-bearing SAC305 solder alloys showed much lower $m_{0}$ and $k$ values than the conventional $\mathrm{Sn} 37 \mathrm{~Pb}$ solders which indicated that the $\mathrm{Co} / \mathrm{Ni}$-bearing SAC305 solder alloys possessed of excellent thermal fatigue resistance and higher creep resistance. For the lead free solder alloys, high temperature aging led to microstructural coarsening. After aging, the $m_{0}$ value increased meanwhile the $k$ value decreased for the Co/Ni-bearing SAC305 solders. Furthermore, the two parameters showed a converse change tendency between the conventional $\mathrm{Sn} 37 \mathrm{~Pb}$ and $\mathrm{Co} / \mathrm{Ni}$-bearing SAC305 solders after high temperature aging, which implied that they have different creep mechanism. It can be deduced that, for the conventional Sn37Pb solder, the grain boundary slide is the dominant creep mechanism, whereas the Co/Ni-bearing SAC305 solders showed a dislocation glide/climb creep mode. [doi:10.2320/matertrans.MF200803]
\end{abstract}

(Received November 16, 2007; Accepted January 24, 2008; Published March 27, 2008)

Keywords: thermal fatigue resistance, creep properties, lead-free solder, strain rate change tensile test

\section{Introduction}

With the miniaturization of the electronic products, better mechanical performance and higher reliability are required for the solder materials. Even during service conditions, the solder alloys are subjected to creep and fatigue deformation duo to their low melting point. Accordingly, the anti-creep ability and the thermal fatigue resistance of the solder alloys are much concerned. ${ }^{1-3)}$ Since the test parameters used in the traditional thermal fatigue properties test are various, the results are not universal, in addition, the test cost is high and the test period is long. ${ }^{4)}$ The SRCT test is a simple mechanical test method developed by professor $\mathrm{T}$. Takemoto et al. ${ }^{5)}$ In this test method, the strain rate is alternated between two given values at given time intervals. The strain rate sensitivities index (SRSI), i.e. the $m$ value, and its gradient $k$ can be conveniently calculated using the load-strain curve obtained from the SRCT test. The $m_{0}$ value was accordant with the creep resistance while the $k$ value implied the stability of the creep resistance during the deformation process. Because the relative low melting temperature, even in the room temperature the homologous temperature of Snbased solders is over 0.6 , which indicates that the timedependent creep deformation is dominant during the thermal fatigue damage for the Sn-based lead free solder alloys. So, the two parameters obtained from the SRCT test, $m_{0}$ and $k$ could be applied to evaluate the resistance of thermal fatigue and the creep properties of lead free solder alloys. T. Takemoto and I. Shoji et al. used the two parameters to evaluate the thermal fatigue resistance for several lead-free solder alloys and obtained satisfactory results. ${ }^{6-10)}$

It has been proved that the minor element addition is a simple and effective way of modifying the microstructural and mechanical properties of lead free solder alloys. Owing to the relatively low cost and toxicity, the Co and Ni have driven more concerns in the recent years. ${ }^{11,12)}$ In the present work, it was noticed that the $m_{0}$ and $k$ values showed different change tendency for the SAC305 solder alloys and the traditional $\mathrm{SnPb}$ solders before and after high temperature aging. The two parameters, $m_{0}$ and $k$ and their change tendency were used to analyze the creep properties, as well as the estimation of the thermal fatigue resistance for the Co/Ni-bearing SAC305 solders.

\section{Experimental Procedures}

Four sorts of lead-free solders, Sn-3.0 mass\%Ag-0.5 mass $\% \mathrm{Cu}, \quad \mathrm{Sn}-3.0$ mass $\% \mathrm{Ag}-0.5$ mass $\% \mathrm{Cu}-0.2$ mass $\% \mathrm{Co}$, Sn-3.0 mass $\% \mathrm{Ag}-0.5$ mass $\% \mathrm{Cu}-0.1$ mass $\% \mathrm{Ni}$, and $\mathrm{Sn}-3.0$ mass $\% \mathrm{Ag}-0.5$ mass $\% \mathrm{Cu}-0.2$ mass $\% \mathrm{Co}-0.1$ mass $\% \mathrm{Ni}$ (Hereafter, these alloys were designated as SAC305, SAC3050.2Co, SAC305-0.1Ni, and SAC305-0.2Co0.1Ni, respectively.) were prepared for the experiments. The solders were remelted at about $317^{\circ} \mathrm{C}$ in a graphite crucible and then cast into a dumbbell-shaped steel moulds. The specification of the tensile test specimens is according to JIS Z 6198-2.

The SRCT test was conducted at room temperature using the Instron tensile test machine. Figure 1(a) depicted a typical test load-strain profile obtained from SRCT test. There are two strain rates applied at intervals in the tensile procedure. The high strain rate is $\dot{\varepsilon}_{1}=1 \times 10^{-3} \mathrm{~s}^{-1}$ (the corresponding cross-head speed is $3 \mathrm{~mm} / \mathrm{min}$.) and the low strain rate is $\dot{\varepsilon}_{2}=1 \times 10^{-4} \mathrm{~s}^{-1}$ (the corresponding crosshead speed is $0.3 \mathrm{~mm} / \mathrm{min}$.). The standing intervals are $50 \mathrm{~s}$ for $\dot{\varepsilon}_{1}$ and 30 s for $\dot{\varepsilon}_{2}$, respectively. $30 \mathrm{~s}$ is enough to achieve quasic-steady state for $\dot{\varepsilon}_{2}$.

Figure 1(b) illustrated the procedure how to calculate the SRSI, i.e. the $m$ value, using a typical load-strain curve obtained from the SRCT test. The $m$ was defined by the following power-law equation: 


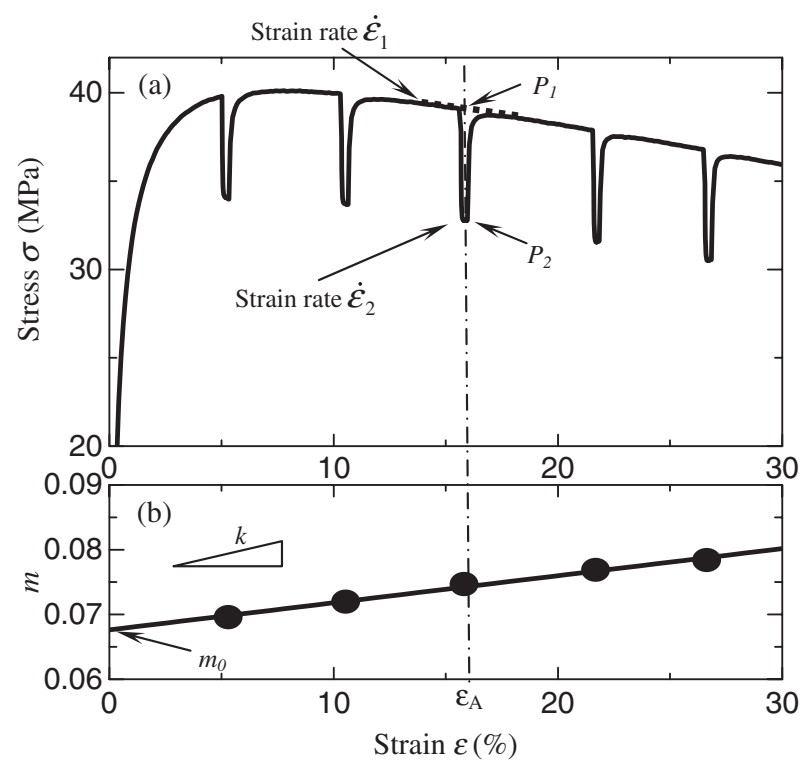

Fig. 1 Schematic diagram of the strain rate change tensile test method (a) the typical stress-strain test plot, and (b) the obtained $m-\varepsilon$ plot.

$$
\sigma=A \dot{\varepsilon}^{m}
$$

Here, $\sigma$ denotes the tensile stress, $\dot{\varepsilon}$ the strain rate, $A$ material constant, and $m$ is the SRSI.

So, the $m$ value at certain strain value could be calculated by the following equation:

$$
m=\frac{\log \left(\sigma_{1} / \sigma_{2}\right)}{\log \left(\dot{\varepsilon}_{1} / \dot{\varepsilon}_{2}\right)}=\frac{\log \left(P_{1} / P_{2}\right)}{\log \left(\dot{\varepsilon}_{1} / \dot{\varepsilon}_{2}\right)}
$$

Where $P_{1}$ is the load force under the high strain rate $\dot{\varepsilon}_{1}=1 \times 10^{-3} \mathrm{~s}^{-1}$, and $P_{2}$ is the load force under the low strain rate $\dot{\varepsilon}_{2}=1 \times 10^{-4} \mathrm{~s}^{-1}$. The $P_{2}$ could be directly obtained from the stress-strain profile in Fig. 1(a). Meanwhile, the $P_{1}$ could be calculated by extrapolating the two contextual profile segments under the high strain rate $\dot{\varepsilon}_{1}$ at the same strain point, $\varepsilon_{\mathrm{A}}$. The plot between $m$ and strain $\varepsilon$ showed an almost linear relationship within the range of present experiment as shown in Fig. 1(b). The $m$ at strain rate zero, i.e. $m_{0}$, can be obtained by extrapolating the $m-\varepsilon$ plot to the vertical axial. Moreover, the gradient $k$ of this fitting line is also obtained.

In order to investigate the effect of high temperature storage on the thermal fatigue resistance and the creep properties, the solders were aged in an oil bath at $150^{\circ} \mathrm{C}$ for $168 \mathrm{~h}$. The composition of Co-Sn intermetallics was identified by electron probe micro-analysis (EPMA).

\section{Results and Discussion}

\subsection{Strain rate sensitivity index $\boldsymbol{m}$ and its gradient $\boldsymbol{k}$}

As depicted in the experiment procedures, the strain rate sensitivity index, $m$, can be calculated from the designed SRCT test. According to the test results, the $m$ value is not a constant during the whole tensile process. Generally, with the increase of the elongation deformation, the $m$ value becomes larger, that means the $m$ is strain-dependent. Obviously, the $m_{0}$ obtained from the SRCT test eliminated the effect of strain, i.e., strain-independent. The $m$ value is an effective
Table 1 The quantitative analysis results of $\mathrm{Co} / \mathrm{Ni}-\mathrm{Sn}$ intermetallics in Co/Ni-bearing SAC305 solders. (unit: at\%).

\begin{tabular}{ccccccc}
\hline & $\mathrm{Sn}$ & $\mathrm{Cu}$ & $\mathrm{Ag}$ & $\mathrm{Co}$ & $\mathrm{Ni}$ & Phase \\
\hline SAC305-0.2Co & 66.4 & 1.2 & 0 & 32.6 & - & $\mathrm{CoSn}$ \\
SAC305-0.1Ni & 47.1 & 39.8 & 0.3 & - & 12.8 & $(\mathrm{Cu}, \mathrm{Ni})_{6} \mathrm{Sn}_{5}$ \\
SAC305-0.2Co0.1Ni & 65.7 & 0.9 & 0 & 23.2 & 10.2 & $(\mathrm{Co}, \mathrm{Ni}) \mathrm{Sn}_{2}$ \\
\hline
\end{tabular}

parameter to analyze the materials creep properties. Generally, the lower the $m$ value is, the higher the creep resistance is. The dislocation climb (DC) creep showed a much higher $m$ value than that of the grain boundary slide (GBS) creep pattern. ${ }^{13,14)}$

Furthermore, the gradient $k$ reveals the stability of the $m$ value when the deformation increasing continuously during the tensile test process. In theory, zero $k$ means the $m$ is a constant during the whole tensile process before fracture, which implied the creep resistance is not deteriorated during the whole tensile test process. On the contrary, a plus $k$ value indicated the decrease of the creep resistance with the increase of the deformation. So, the gradient $k$ is a good index to evaluate the stability of the creep process.

\subsection{The microstructural characterization of $\mathrm{Co} / \mathrm{Ni}$ - bearing SAC305 solder alloys}

It has been widely known that several phases co-exist in the SAC305 solder alloy, namely, the $\beta-\mathrm{Sn}, \mathrm{Ag}_{3} \mathrm{Sn}$ and $\mathrm{Cu}_{6} \mathrm{Sn}_{5}$. The $\mathrm{Co} / \mathrm{Ni}$ additives induced the formation of some new compound phases and microstructural modification for the SAC305 solder alloy. Figure 2 illustrated that some new intermetallics were generated after the addition of minor $\mathrm{Co} /$ Ni. The quantitative analysis results by EPMA indicated that the new intermetallics were $\mathrm{CoSn}_{2}$ and $(\mathrm{Co}, \mathrm{Ni}) \mathrm{Sn}_{2}$ for the SAC305-0.2Co and SAC305-0.2Co0.1Ni alloys, respectively. For the SAC305-0.1Ni alloy, the new intermetallics was $(\mathrm{Cu}, \mathrm{Ni})_{6} \mathrm{Sn}_{5}$, as shown in Table 1 .

Figure 3 shows the microstructure after high temperature aging at $150^{\circ} \mathrm{C}$ for $168 \mathrm{~h}$. It is clear that substantial microsturctural coarsening had occurred. For the rapid diffusion of $\mathrm{Ag}$ and $\mathrm{Cu}$ in the $\mathrm{Sn}$ matrix under high temperature, the superfine $\mathrm{Ag}_{3} \mathrm{Sn}$ and $\mathrm{Cu}_{6} \mathrm{Sn}_{5}$ particles inside the eutectic network grew and coalesced rapidly.

Generally, the mechanical properties are correlated with the microstructures, the formation of the new intermetallics after the addition of $\mathrm{Co} / \mathrm{Ni}$ and the microstructural coarsening after high temperature storage will change the thermal fatigue resistance, as well as the creep properties.

\subsection{The effects of Co and Ni additives on the $m_{0}$ and $k$}

The relationship between the $m$ value and the strain $\varepsilon$ was illustrated in Fig. 4. The discrete $m$ value data are fitted by least-squares method and the intercept of the fitting lines on the vertical axial is the corresponding $m_{0}$ value. It is clear that the SAC305 solder has the lowest $m_{0}$ value, as well as the lowest $k$ value. The sole addition of Co or Ni showed similar effect on the $m_{0}$ and $k$. Both of them increased the $m_{0}$ slightly, but scarcely affected the $k$ value. However, the dual addition of Co-Ni raised the $k$ value significantly.

Figure 5 depicted the location of the four tested lead-free solders and the conventional $\mathrm{Sn} 37 \mathrm{~Pb}$ solder in the $m_{0}-k$ 


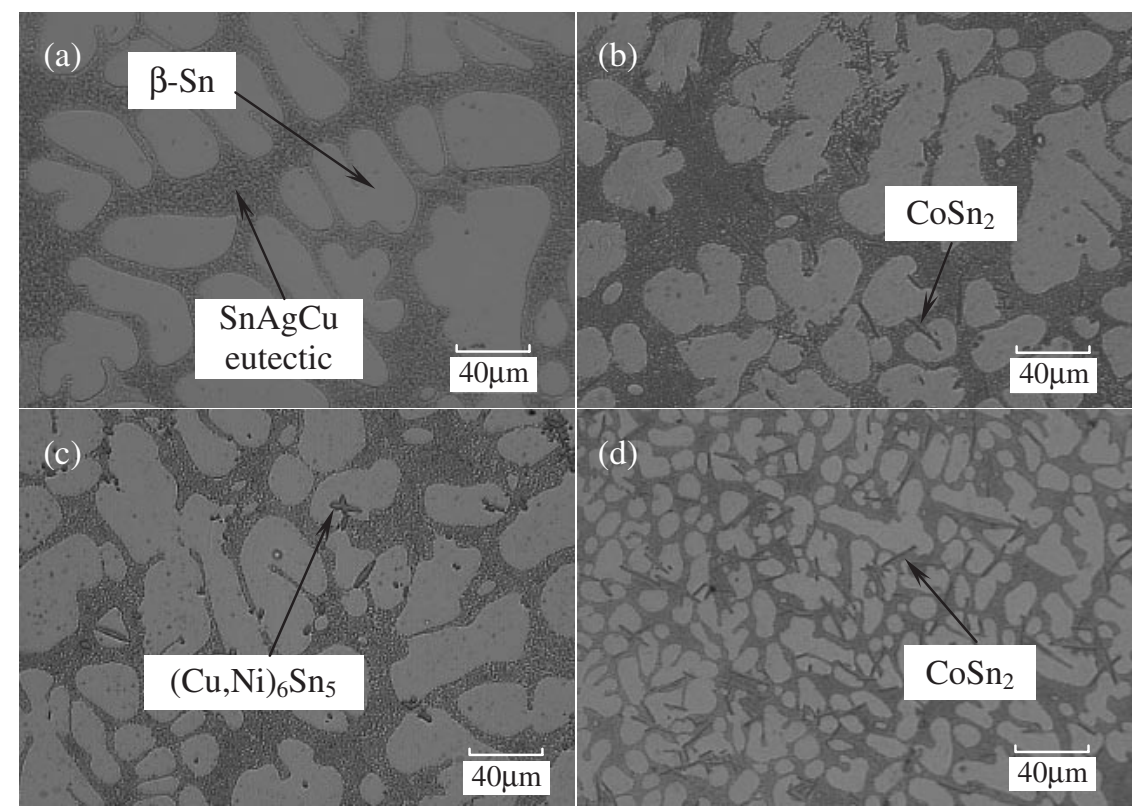

Fig. 2 The microstructure in the as-cast condition of (a) SAC305, (b) SAC305-0.2Co, (c) SAC305-0.1Ni, and (d) SAC305-0.2Co0.1Ni.
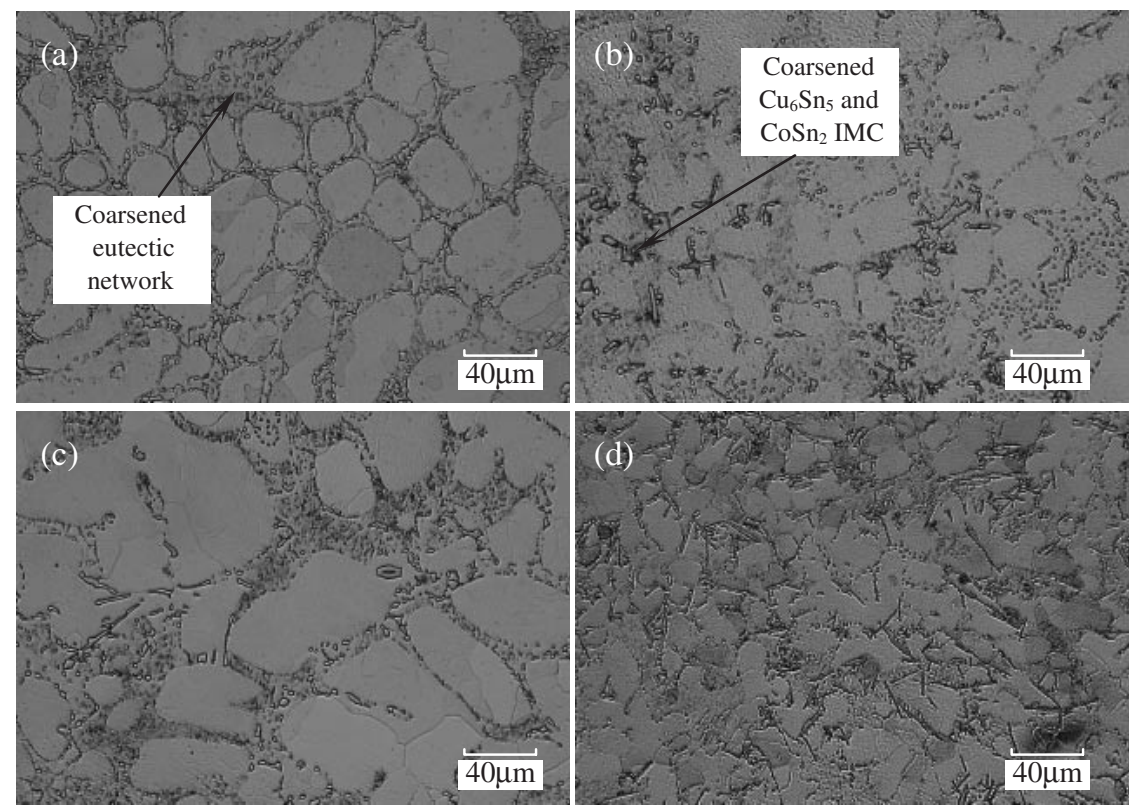

Fig. 3 The microstructure after $168 \mathrm{~h}$ aging at $150^{\circ} \mathrm{C}$ of (a) SAC305, (b) SAC305-0.2Co, (c) SAC305-0.1Ni, and (d) SAC305$0.2 \mathrm{Co} 0.1 \mathrm{Ni}$.

coordinate plane. The open symbols and the correlated solid symbols denoted the as-cast condition and after aging condition for the same alloy, respectively. Compared with the conventional $\mathrm{Sn} 37 \mathrm{~Pb}$ eutectic solder, the four sorts of lead-free solders showed much lower $m_{0}$ and $k$ values. In addition, it is noticed that the SAC $305-0.2 \mathrm{Co} 0.1 \mathrm{Ni}$ solder showed a larger $k$ value than the other lead-free solder alloys.

High temperature aging treatment has notably effect on the $m_{0}$ and $k$ value for the solder alloys. For the lead-free solders, the $m_{0}$ value increased while the $k$ value decreased. For the $\mathrm{Sn} 37 \mathrm{~Pb}$ solder, the effects were just contrary, the $m_{0}$ decreased meanwhile the $k$ increased after high temperature aging treatment.

\subsection{Estimation of the thermal fatigue resistance}

Based on the earlier experiment results conducted by $T$. Takemoto et al., the $m_{0}$ and $k$ are the effective indices for the thermal fatigue resistance rank of several solder alloys, that is, the lower the $m_{0}$ and $k$ values are, the higher the thermal fatigue resistance rank is. Compared to the SAC305 baseline, the $\mathrm{Co} / \mathrm{Ni}$ additives just changed the $m_{0}$ and $k$ values slightly. Accordingly, it can be deduced that the effect of $\mathrm{Co} / \mathrm{Ni}$ additives on the thermal resistance is very slight. Compared to the $\mathrm{Sn} 37 \mathrm{~Pb}$ solder, all the four sorts of lead-free solder alloys should possess of excellent thermal fatigue resistance due to their relatively lower $m_{0}$ and $k$ value. After aging at $150^{\circ} \mathrm{C}$ for $168 \mathrm{~h}$, the parameters were still much lower than 


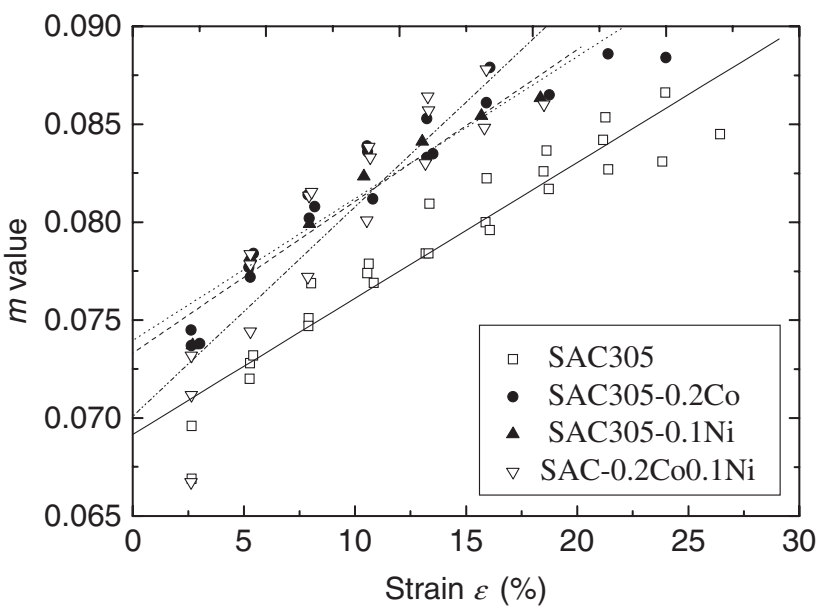

Fig. 4 The relationship between the $m$ and the strain $\varepsilon$.

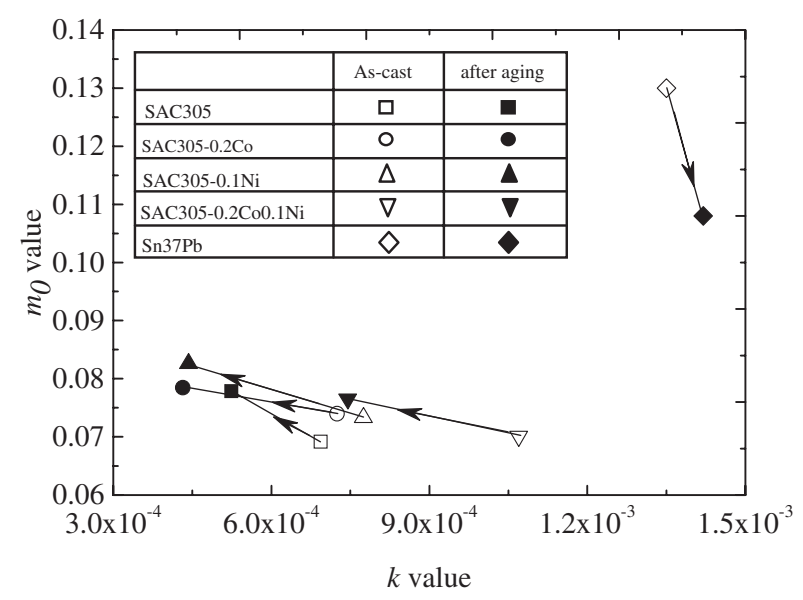

Fig. 5 The location of several solders in the $m_{0}-k$ coordinate plane.

that of the Sn37Pb, which indicated that the SAC305-based lead-free solder alloys possessed excellent thermal fatigue resistance even after high temperature storage.

\subsection{Evaluation of the creep properties}

As shown in Fig. 5, the Co/Ni-bearing SAC305 solder alloys showed much higher $m_{0}$ value than the conventional $\mathrm{Sn} 37 \mathrm{~Pb}$ solders both in the as-cast condition and after high temperature aging. Such a result indicated that the $\mathrm{Co} / \mathrm{Ni}$ bearing SAC305 solder alloys possessed of better creep resistance than the $\mathrm{Sn} 37 \mathrm{~Pb}$ solder.

After aging, the $m_{0}$ and $k$ value of lead-free solders and the conventional $\mathrm{Sn} 37 \mathrm{~Pb}$ solders showed different change tendency, which implied different creep mechanism for them. The conventional $\mathrm{Sn} 37 \mathrm{~Pb}$ solder consists of two constituent phase, i.e., the alternated tin-rich phase and lead-reach phase. During high temperature aging, the average grain size both of the tin-rich and the lead-rich phases increased. Meanwhile, the $m_{0}$ also decreased, as shown in Fig. 5. In other words, the creep resistance increased after aging for the conventional $\mathrm{Sn} 37 \mathrm{~Pb}$ sloder. It is accordant with the grain boundary slide (GBS) type creep mechanism, that is, the larger the average grain size, the higher the creep resistance is. Accordingly, it can be conclude that GBS is the dominant creep mechanism for the $\mathrm{Sn} 37 \mathrm{~Pb}$ solders.

The SAC-based lead-free solders consist typically of $\beta$-Sn and $\mathrm{Ag}_{3} \mathrm{Sn}_{-} \mathrm{Cu}_{6} \mathrm{Sn}_{5}-\beta$-Sn ternary eutectic network. As-cast condition, the superfine $\mathrm{Ag}_{3} \mathrm{Sn}$ and $\mathrm{Cu}_{6} \mathrm{Sn}_{5}$ intermetallics dispersed in the eutectic network uniformly, as shown in Fig. 2. These hard and well-dispersed intermetallis acted as the discrete obstacles to block the movement of the dislocation, which is the main reason that the SAC-based lead-free solders presented better creep resistance than the $\mathrm{Sn} 37 \mathrm{~Pb}$ solders under the room temperature. During high temperature aging, the superfine $\mathrm{Ag}_{3} \mathrm{Sn}$ and $\mathrm{Cu}_{6} \mathrm{Sn}_{5}$ particles in the eutectic network grew and coalesced into together significantly. So, the microstructural coarsening of the leadfree solder alloys after aging attributed to the coalescence and the amount decrease of these intermetallics particles instead of the growing of the $\beta$-Sn dendrites. On the other hand, the increase of $m_{0}$ after aging implied that the anti-creep ability decreased, which is very different to that of the $\operatorname{Sn} 37 \mathrm{~Pb}$ solder. A reasonable explanation for such a result is the growing and coalescence of the $\mathrm{Ag}_{3} \mathrm{Sn}$ and $\mathrm{Cu}_{6} \mathrm{Sn}_{5}$ intermetallics reduced the obstacles for the dislocation movement after aging treatment. In addition, the $m_{0}$ value of the leadfree solder alloys is much lower than that of the conventional $\mathrm{Sn} 37 \mathrm{~Pb}$ solder alloy. It is accordant with the dislocation glide/climb (DC) type creep, that is, the lower the amount of the obstacle particles, the lower the creep resistance is. Accordingly, it can be concluded that the dislocation glide/ climb is the dominant creep mechanism for the SAC-based lead-free solders.

Compared with the SAC305 baseline, the SAC305$0.2 \mathrm{Co} 0.1 \mathrm{Ni}$ alloy showed a higher $k$ value. A higher $k$ value indicated a lower stability of the creep resistance during deformation. It could be explained by the different of the microstructure. As shown in Fig. 2(d), the $\mathrm{CoSn}_{2}$ intermetallics in SAC305-0.2Co0.1Ni solder are very thin and sharp, in addition, these intermetallics are harder and more brittle than the Sn matrix. Along with the increase of the deformation during tensile test, the micro-cracks are apt to initiate along these $\mathrm{CoSn}_{2}$ intermetallics, as shown in Fig. 6. The easily initiating of the micro-cracks along the sharp and brittle $\mathrm{CoSn}_{2}$ intermetallics is the main reason for the degradation of the creep resistance.

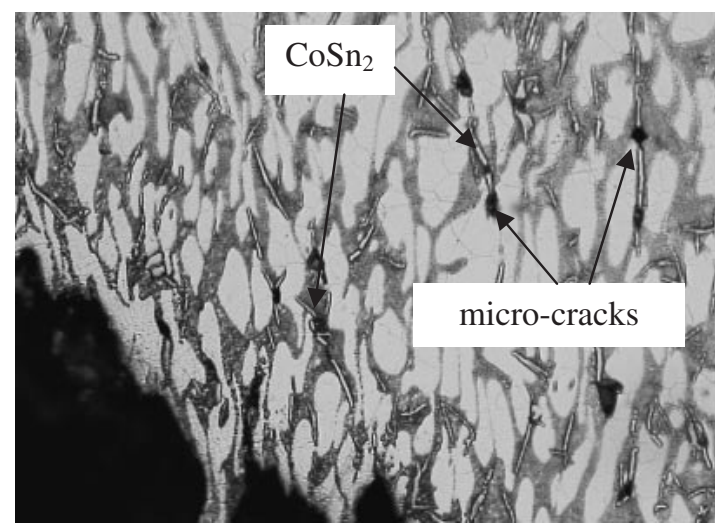

Fig. 6 The cross-sectional micrographs near the fracture surface after tensile test of the SAC305-0.2Co0.1Ni. 


\section{Conclusions}

To evaluate the effect of the $\mathrm{Co} / \mathrm{Ni}$ additives on the thermal fatigue resistance and the creep properties of the SAC305 lead-free solder alloys, a strain rate change tensile test method was conducted. The results are summarized as follows.

(1) The $m_{0}$ and $k$ values of the Co/Ni-bearing SAC305 leadfree solders are lower than that of the $\mathrm{Sn} 37 \mathrm{~Pb}$ solder. It indicates that the Co/Ni-bearing SAC305 solders showed a better thermal fatigue resistance than the conventional $\mathrm{Sn} 37 \mathrm{~Pb}$ solder.

(2) The Co/Ni-bearing SAC305 solder alloys showed much lower $m_{0}$ value than the conventional $\mathrm{Sn} 37 \mathrm{~Pb}$ solders both in the as-cast condition and after high temperature aging. Such a result indicated that the $\mathrm{Co} / \mathrm{Ni}$-bearing SAC305 solder alloys possessed of better creep resistance than the $\mathrm{Sn} 37 \mathrm{~Pb}$ solder. (3) After high temperature aging, the contrary change tendency of the $m_{0}$ and $k$ values for the SAC305 lead-free solders and the conventional $\mathrm{Sn} 37 \mathrm{~Pb}$ solders revealed that they have different creep mechanism. It can be deduced that the GBS is the dominant creep mechanism for the $\mathrm{Sn} 37 \mathrm{~Pb}$ eutectic solder, meanwhile, the SAC305 lead-free solders showed DC type creep mode.

\section{REFERENCES}

1) F. Guo et al.: J. Electron. Mater. 30 (2001) 1222-1227.

2) S. Wiese and K.-J. Wolter: Microelectron. Reliab. 47 (2007) 223-232.

3) A. J. van Roosmalen and G. Q. Zhang: Microelectron. Reliab. 46 (2006) 1403-1414.

4) I. Shoji, H. Mori and Y. Orii: Microelectron. Reliab. 44 (2004) 269274.

5) T. Takemoto, A. Matsunawa and M. Takahashi: J. Mater. Sci. 32 (1997) 4077-4084.

6) T. Takemoto et al.: Adv. Electron. Packag. EEP-19 (1997) 1623-1628.

7) T. Takemoto, M. Tadahashi and A. Matsunawa: Adv. Electron. Packag. EEP-26 (1999) 575-580.

8) I. Shoji, K. Yasuda and T. Takemoto: Mater. Trans. 46 (2005) 23292334.

9) T. Takemoto: Materia Japan. 38 (1999) 942-946.

10) T. Takemoto et al.: Quarterly Journal of The JWS. 24 (1998) 87-92.

11) I. de Sousa et al.: Proc. 56th ECTC, 1454-1461.

12) I. E. Anderson: J. Mater. Electron. 18 (2007) 55-76.

13) A. Delatorre, P. Adeva and M. Aballe: J. Mater. Sci. 26 (1991) 43514354.

14) A. R. Geranmayeh and R. Mahmudi: J. Mater. Sci. 40 (2005) 33613366 . 